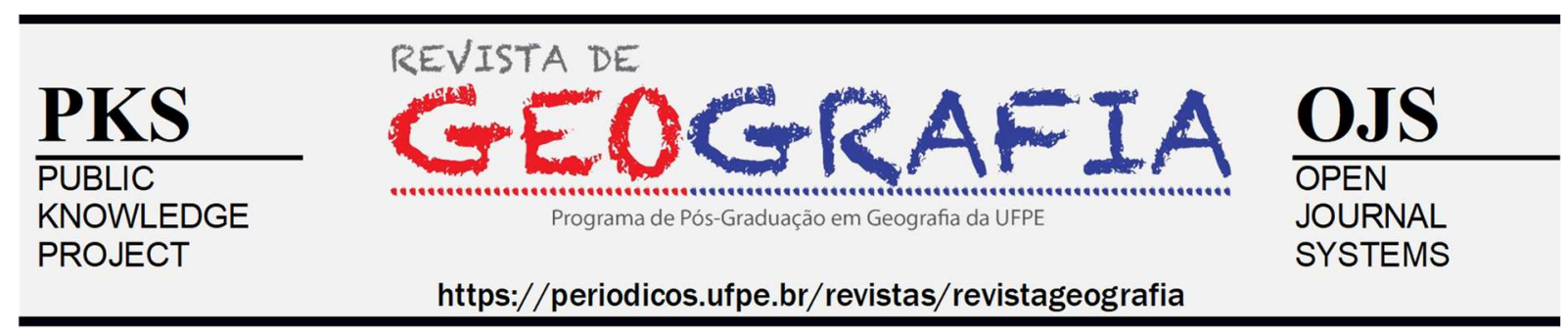

\title{
CARACTERIZAÇÃO GEOMORFOMÉTRICA E PEDOLÓGICA DA BACIA HIDROGRÁFICA DO RIO BAGAGEM (GOIÁS - GO)
}

\author{
Fernanda Alves Oliveira Ferreira ${ }^{1}$, Ana Carolina Santomé Franco², José Carlos de Souza ${ }^{3}$ \\ 1 Universidade Estadual de Goiás - Programa de Pós Graduação em Geografia. E-mail: \\ fernanddafferreira@hotmail.com \\ 2 Universidade Estadual de Goiás - Programa de Pós Graduação em Geografia. E-mail: \\ carolinafs93@hotmail.com \\ ${ }^{3}$ Universidade Estadual de Goiás - Programa de Pós Graduação em Geografia. E-mail: jose.souza@ueg.br
}

Artigo recebido em 24/04/2020 e aceito em 30/06/2020

\begin{abstract}
RESUMO: O objetivo deste trabalho foi caracterizar os aspectos geomorfométricos e pedológicos da bacia hidrográfica do rio Bagagem, no município de Goiás - GO, com vistas ao diagnóstico das condições ambientais da bacia. Foram levantadas características dos tipos de solos e parâmetros morfométricos e hidrológicos da bacia, por meio de técnicas de geoprocessamento. Os resultados indicaram que a bacia hidrográfica do rio Bagagem possui uma dinâmica geomorfométrica e hidrológica com indicação de baixo a médio potencial para ocorrência de enchentes, devido a seu formato oblongo. A rede de drenagem apresenta cinco ordens e uma densidade de drenagem regular e dendrítica. O coeficiente de manutenção indica dificuldade na manutenção de drenagens perenes. A alta amplitude altimétrica e de declividades, associada aos solos e as curvaturas plana e de perfil, sugerem uma preocupação acerca das formas de uso e manejo dos solos da bacia, no intuito de mitigar processos erosivos e impactos nos corpos hídricos.
\end{abstract}

Palavras-chave: Dinâmica hidrológica; Morfometria; Solos; Gestão de bacias.

\section{GEOMORPHOMETRIC AND PEDOLOGICAL CHARACTERIZATION OF BAGAGEM RIVER WATERSHED (GOIÁS, GOIÁS, BRAZIL).}

\begin{abstract}
The objective of this paper was to characterize the geomorphometric and pedological aspects of Bagagem river watershed, in the municipality of Goiás (Brazil), for diagnose the environmental conditions of the watershed. Characteristics of soil types and morphometric and hydrological parameters of the watershed were surveyed, through geoprocessing techniques. The results indicated that the Bagagem river watershed has a geomorphometric and hydrological dynamics with an indication of low to medium potential for the occurrence of floods, due to its oblong shape. The drainage network has five orders and a regular and dendritic drainage density. The maintenance coefficient indicates difficulty in maintaining perennial drains. The high variability altitude and slope, associated with the types of soils and the flat and profile curvatures, suggest a concern about the ways of use and management, management of watershed soils, in order to mitigate erosion process and impacts on water bodies.
\end{abstract}

Keywords: Hydrological dynamics; Morphometric; Soils; Basin Management. 


\section{INTRODUÇÃO}

As bacias hidrográficas são consideradas sistemas ambientais abertos, células básicas de análise geoambiental e unidades de planejamento e gestão integrados dos recursos naturais. Como sistema ambiental, uma bacia deve ser analisada de forma integrada, considerando os componentes, os processos e as interações, no sentido de compreender as causas e consequências das intervenções humanas sobre esses geossistemas e seus desdobramentos sobre a dinâmica da paisagem (BOTELHO; SILVA, 2010; BERTONI; LOMBARDI NETO, 2014).

O geossistema nos estudos geográficos é compreendido como um recorte espacial natural, onde ocorrem fluxos constantes de energia e matéria, sujeitas a variações no espaço e no tempo, devido a inter-relação dos elementos dos meios físico, biótico e antrópico. É uma abordagem teórico-metodológica que surgiu sob influência da Teoria Geral dos Sistemas e amplamente aplicado à análise ambiental integrada (SOTCHAVA, 1977; TROPPMAIR, 2004; BERTRAND, 2004).

Desta forma, do ponto de vista do planejamento e da gestão, a bacia pode ser entendida como unidade preferencial para o planejamento e gestão ambiental por abranger um conjunto de variáveis ambientais e antrópicas, importantes para o diagnóstico e manejo de determinado espaço, tais como: geologia, relevo, clima, solos, cobertura vegetal e os processos de uso e ocupação do solo (LEAL et al., 2003; SOUZA; OLIVEIRA, 2017).

Nesse sentido, a gestão dos recursos hídricos é um mecanismo importante para a gestão do território em uma bacia hidrográfica e, a perspectiva da gestão deve integrar os aspectos dos meios físico, biótico e socioeconômicos, que interferem no uso dos recursos hídricos, com vistas à proteção ambiental. As modelagens de caracterização do sistema de drenagem e dos aspectos morfométricos, em uma bacia hidrográfica, podem subsidiar planos de ação e gestão que visam a conservação do solo e água (PORTO; PORTO, 2008; MAGESH et al., 2013; AHER; ADINARAYANA; GORANTIWAR, 2014).

As análises morfométricas de bacias hidrográficas devem ser norteadas por métodos que quantifiquem as interações entre a fisiografia da paisagem e a dinâmica hidrológica, possibilitando assim conhecer a dinâmica fluvial e a relação existente entre os elementos físicos e bióticos de uma bacia (STRAHLER, 1957; FARIA et al., 2009). A geomorfometria é o estudo matemático das formações e configurações da superfície de uma determinada área. Este estudo 
pode indicar características geométricas, da rede de drenagem e aspectos do relevo (CAMPANHARO, 2010).

A análise geométrica da bacia corresponde à análise dos atributos da rede de drenagem e da morfologia (CHRISTOFOLETTI, 1969). Nessa análise são calculadas a densidade da drenagem, densidade dos rios, perímetro, ordem das bacias, índice de circularidade, coeficiente de sinuosidade hidráulico, coeficiente de manutenção, índice de rugosidade, relação de relevo dentre outras características.

De forma igualmente importante, a análise pedológica é imprescindível para a avaliação e planejamento do uso do solo, bem como para a recuperação de áreas degradadas. Estudos nesta direção vêm apresentando relações diretas entre a textura do solo com a mudança na paisagem, vegetação e influência na declividade, principalmente em horizontes superficiais (SHELEME, 2011).

Os índices geomorfométricos, associados à caracterização pedológica, podem contribuir na compreensão das fragilidades ambientais, frente às intervenções antrópicas no ambiente, subsidiando práticas adequadas de manejo e uso do solo (LOPES, et al., 2018). Em vista disto, este artigo traz como objetivo caracterizar os aspectos geomorfométricos e pedológicos da bacia hidrográfica do rio Bagagem, no município de Goiás, Estado de Goiás, com vistas ao diagnóstico das condições ambientais da bacia. A bacia fornece água para abastecimento urbano e tem apresentado importantes intervenções humanas, especialmente nas nascentes, resultando na alteração da dinâmica hidrológica dos cursos d'água.

\section{MATERIAIS E MÉTODOS}

Localização e características da área de estudo

A bacia hidrográfica do rio Bagagem (BHRB) compõe o sistema de drenagem da Alta Bacia do rio Vermelho, está localizada entre as coordenadas $15^{\circ} 55^{\prime} 50^{\prime \prime}$ e $16^{\circ} 02$ ' $10^{\prime}$ ' de Latitude Sul e $50^{\circ} 02^{\prime} 30^{\prime \prime}$ e $50^{\circ} 10^{\prime} 50^{\prime \prime}$ de Longitude Oeste. A bacia ocupa uma área de $98,7 \mathrm{~km}^{2}$ e seu território está em sua totalidade no município de Goiás, Estado de Goiás. 
Figura 1 - Mapa de localização da Bacia Hidrográfica do Rio Bagagem (Goiás-GO).

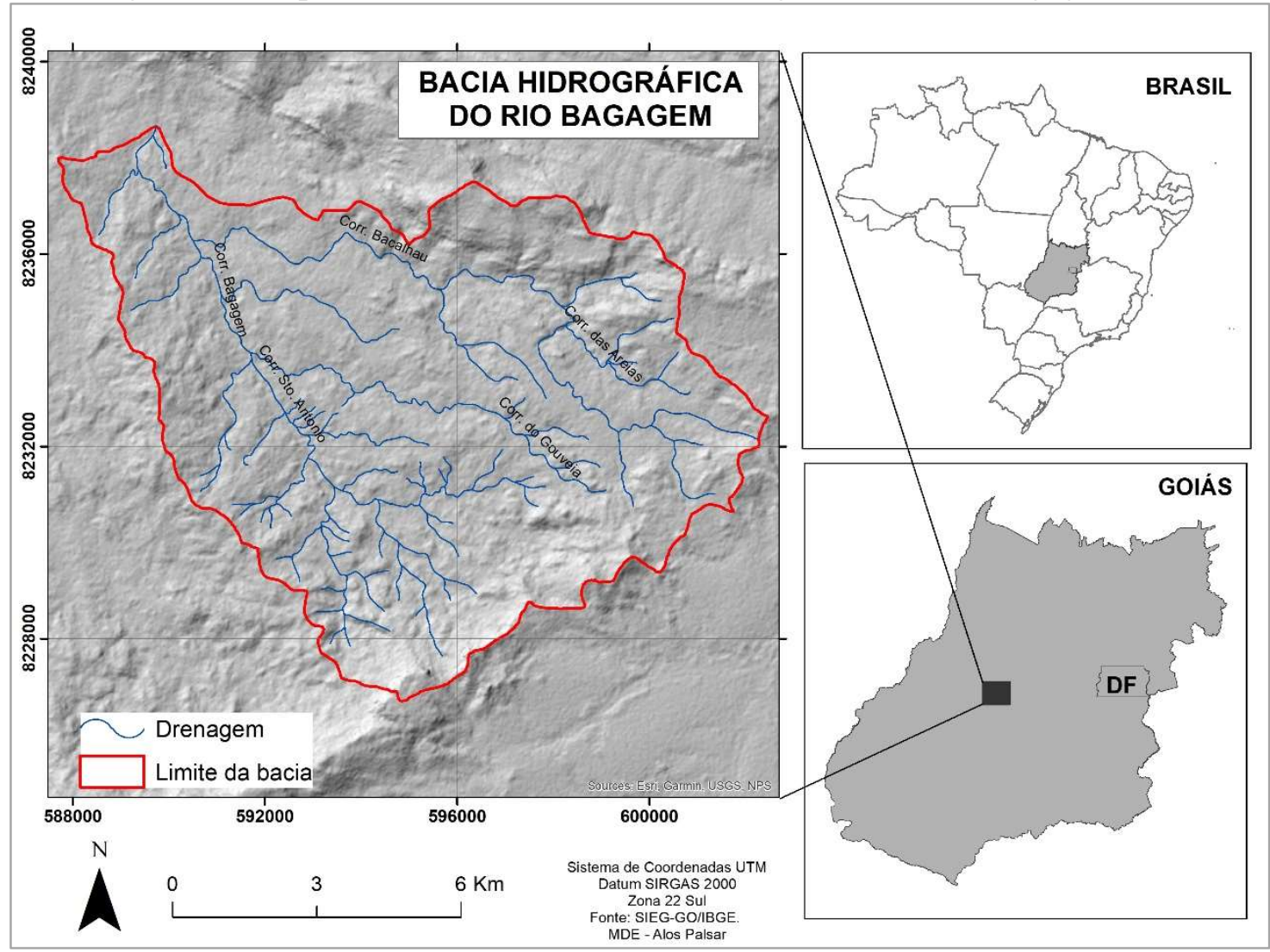

Fonte: Bases vetoriais do Sistema de Geoinformação do Estado de Goiás (SIEG-GO).

O clima da bacia é do tipo Tropical Subúmido (Aw), apresentando verão quente e chuvoso e inverno seco com temperaturas mais amenas. Os meses com as maiores totais de precipitação são novembro, dezembro, janeiro, fevereiro e março, com registros acima de 200 milímetros. A bacia apresenta altas temperaturas ao longo do ano, com médias mensais variando de 23 a $28{ }^{\circ} \mathrm{C}$ (CAVALCANTI; LOPES; PONTE, 2008; VIEIRA; FERREIRA; FERREIRA, 2014).

\section{Caracterização Geométrica}

A caracterização geométrica da bacia e do sistema de drenagens foi feita a partir da aplicação das equações apresentadas na Tabela 1. Na mesma tabela também são apresentadas as definições e alguns parâmetros de cada variável geomorfométrica utilizada na caracterização. 
Tabela 1: Caracterização Geométrica da Bacia Hidrográfica do Rio Bagagem (Goiás - GO).

\begin{tabular}{|c|c|c|}
\hline Variável & Definições e parâmetros & Equação \\
\hline $\begin{array}{l}\text { Densidade da } \\
\text { drenagem }(\boldsymbol{D} \boldsymbol{d})\end{array}$ & $\begin{array}{l}\text { Relação entre o comprimento total de canais e a área da } \\
\text { bacia onde se considera todos os cursos d'água, tanto os } \\
\text { perenes como os temporários (HORTON, 1945). }\end{array}$ & $D d=\frac{L}{A}$ \\
\hline Perímetro & Distância linear da área da bacia. & $\begin{array}{l}\text { Cálculo automático em } \\
\text { softwares de } \\
\text { geoprocessamento }\end{array}$ \\
\hline Ordem da bacia & $\begin{array}{l}\text { A ordem da bacia está relacionada à ramificação dos } \\
\text { cursos d'água segunda metodologia proposta por } \\
\text { Strahler (1957). }\end{array}$ & $\begin{array}{l}\text { Extração da rede de } \\
\text { drenagem por meio do } \\
\text { modelo digital de } \\
\text { elevação, em softwares de } \\
\text { geoprocessamento. }\end{array}$ \\
\hline $\begin{array}{c}\text { Índice de } \\
\text { circularidade }(\boldsymbol{I} \boldsymbol{c})\end{array}$ & $\begin{array}{l}\text { Relaciona a área da bacia com a área de um círculo. } \\
\text { Valores próximos de } 1 \text { indicam que a bacia possui um } \\
\text { formato mais circular e, valores mais próximos de zero, } \\
\text { formas mais alongadas (CARDOSO et al., 2006). Quanto } \\
\text { mais alongada a bacia, ou seja, com IC próximos de zero, } \\
\text { menores as chances de ocorrência de cheias (LANA; } \\
\text { ALVES; CASTRO, 2001). }\end{array}$ & $I C=\frac{12,57 X A}{P^{2}}$ \\
\hline $\begin{array}{l}\text { Coeficiente de } \\
\text { sinuosidade } \\
\text { hidráulico }(I s)\end{array}$ & $\begin{array}{l}\text { É a razão entre o comprimento do canal principal e o } \\
\text { comprimento máximo da bacia. } \\
\text { Sendo: Retilíneo < < 1,05; Sinuoso 1,05-1,50; } \\
\text { Meandrante }>1,50 \text {; Entrelaçado > 1,80; Anastomosado } \\
>2,00 \text { (MORISAWA, 1975). }\end{array}$ & $I s=\frac{L i}{d v}$ \\
\hline $\begin{array}{l}\text { Fator de forma } \\
\qquad(\boldsymbol{K} \boldsymbol{f})\end{array}$ & $\begin{array}{l}\text { Relação entre a forma da bacia com a forma de um } \\
\text { retângulo. O valor } 1 \text { indica forma retangular. } \\
\text { (VILLELA; MATTOS 1975). }\end{array}$ & $K f=\frac{A}{L i i^{2}}$ \\
\hline $\begin{array}{c}\text { Coeficiente de } \\
\text { manutenção }(\boldsymbol{C m})\end{array}$ & $\begin{array}{l}\text { O } \boldsymbol{C m} \text { representa a área necessária que a bacia deve ter } \\
\text { para manter perene cada quilômetro do sistema de } \\
\text { drenagem (TRAJANO, et al., 2012). }\end{array}$ & $C m=\frac{1}{D d} x 1000$ \\
\hline $\begin{array}{l}\text { Índice de rugosidade } \\
\text { (Ir) }\end{array}$ & $\begin{array}{l}\text { O Ir é a relação entre a amplitude altimétrica e a } \\
\text { densidade da drenagem (CHRISTOFOLETTI, 1980). } \\
\text { Quanto maior for esse índice, maior será o risco de } \\
\text { degradação da bacia quando as vertentes são íngremes e } \\
\text { longas (TRAJANO, et al., 2012). }\end{array}$ & $I r=H x D d$ \\
\hline $\begin{array}{c}\text { Tempo de } \\
\text { concentração }(\boldsymbol{T c})\end{array}$ & $\begin{array}{l}\text { Calcula o tempo de concentração do escoamento, após } \\
\text { um evento chuvoso (PRUSKI; BRANDÃO; SILVA, } \\
\text { 2004). }\end{array}$ & $T c=\frac{4 \sqrt{A}+1,5 L}{0,8 \sqrt{H}}$ \\
\hline
\end{tabular}

Em que: $\boldsymbol{L}=$ comprimento dos canais. $\boldsymbol{L} \boldsymbol{i}=$ comprimento do canal principal. $\boldsymbol{L} \boldsymbol{i \boldsymbol { i }}=$ comprimento do eixo da bacia. $\boldsymbol{A}=$ área da bacia. $\boldsymbol{N}=$ número de canais. $\boldsymbol{p}=$ perímetro. $\boldsymbol{d} \boldsymbol{v}=$ comprimento máximo da bacia. $\boldsymbol{D} \boldsymbol{d}=$ Densidade da drenagem. $\boldsymbol{H}=$ amplitude altimétrica. 


\section{Caracterização Pedológica e Geomorfométrica}

Para a caracterização pedológica foi gerado um mapa de solos, utilizando o software QGIS versão 3.10.3, a partir da base cartográfica elaborada pela Agência Goiana de Assistência Técnica, Extensão Rural e Pesquisa Agropecuária - EMATER-GO. Por meio dessa base foram identificados os seguintes tipos de solos: Cambissolo Háplico, Argissolo Vermelho-Amarelo distrófico, Argissolo Vermelho-Amarelo eutrófico e Neossolo Litólico distrófico.

A caracterização geomorfométrica da bacia foi feita pela elaboração das cartas de declividade (classificação proposta pela Embrapa (2009), hipsometria, curvatura plana, curvatura em perfil e hierarquização da drenagem. As técnicas aplicadas para elaboração desses produtos, ocorreram também em ambiente QGIS, a partir do modelo digital de elevação das imagens do satélite Alos sensor Palsar (Advanced Land Observing Satellite), com resolução espacial de 12,5 metros, adquiridas na plataforma Alaska $<$ https://search.asf.alaska.edu/\#/> e datadas de fevereiro de 2011.

\section{RESULTADOS E DISCUSSÃO}

A BHRB possui elevação mínima de $422 \mathrm{~m}$ e máxima de $1.054 \mathrm{~m}$, apresentando amplitude altimétrica de $632 \mathrm{~m}$. O mapa hipsométrico apresentado na Figura 2 foi elaborado com fatiamento do relevo, com intervalos de 60 metros. Em função da disposição topográfica, as drenagens seguem no sentido Sudeste-Noroeste e as maiores elevações (960-1.054) ocorrem em relevos dobrados e altamente dissecados, com ocorrência predominante de quartzitos. As maiores elevações, que ocorrem na porção Sudeste-Sul da bacia, compreendem a front da Serra Dourada. 
Figura 2 - Hipsometria da BHRB (Goiás - GO).

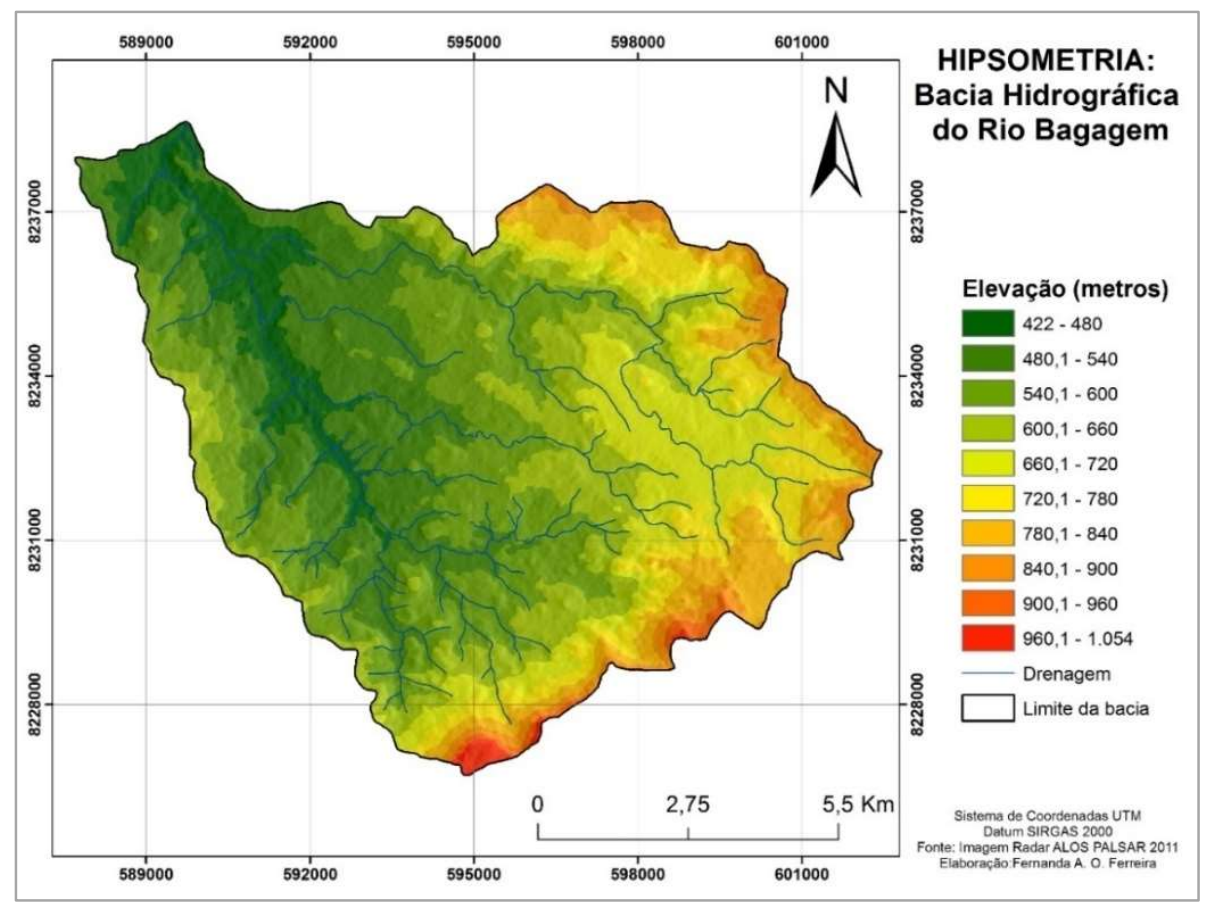

Fonte: Modelo Digital de Elevação - Alos Palsar/2011.

O perfil longitudinal da bacia foi traçado dentro do vale do curso principal (Figura 3), apresentando a variação topográfica no transcurso do rio Bagagem da nascente ao exutório. $\mathrm{O}$ curso principal possui uma extensão de $13,93 \mathrm{~km}$, suas nascentes afloram numa altitude aproximada de $800 \mathrm{~m}$ e tem seu exutório numa elevação de $422 \mathrm{~m}$. As nascentes estão na base (talus) do front da Serra Dourada, que se caracteriza geomorfologicamente como um hogback (HB). A partir deste trecho, o curso atravessa uma área de Morros e Colinas (MC) com forte dissecação, até alcançar uma extensa superfície de aplainamento (SA) (GOIÁS, 2006a).

Figura 3 - Perfil longitudinal do curso principal da BHRB e aspectos geomorfológicos (Goiás - GO).

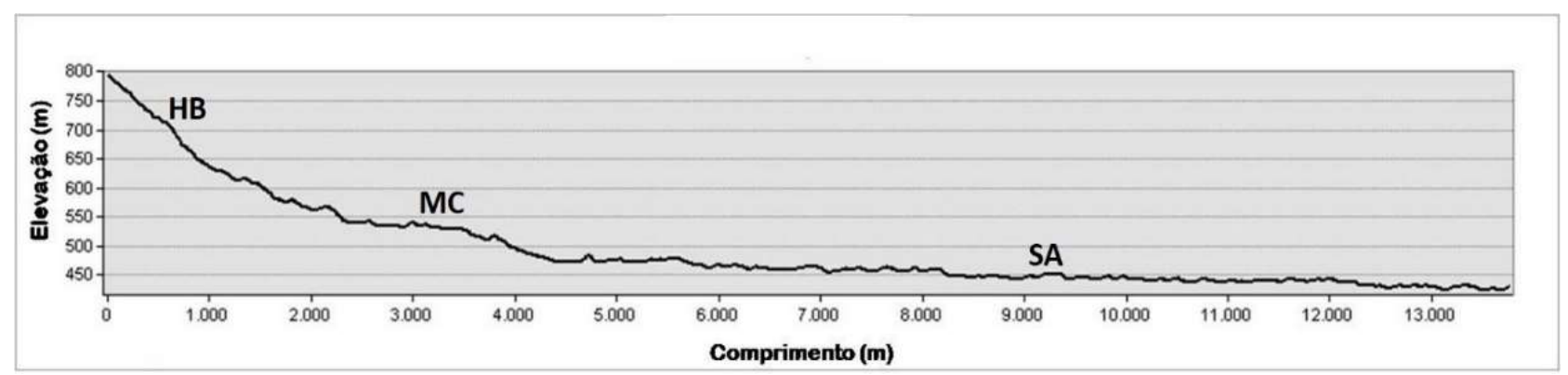

Fonte: Modelo Digital de Elevação - Alos Palsar/2011.

O mapa da Figura 4 apresenta as classes de declividade da bacia e, a Tabela 2, as classes de declividades, as áreas em porcentagem e quilômetros quadrados das respectivas 
formas de relevo. $\mathrm{O}$ intervalo de classe predominante na bacia está entre $8,1 \%$ e $20 \%$, que compreende relevos ondulados e a média dos valores de declividades para toda a bacia, se posicionou entre este intervalo $(15,25 \%)$.

Figura 4 -Declividades da BHRB (Goiás - GO).

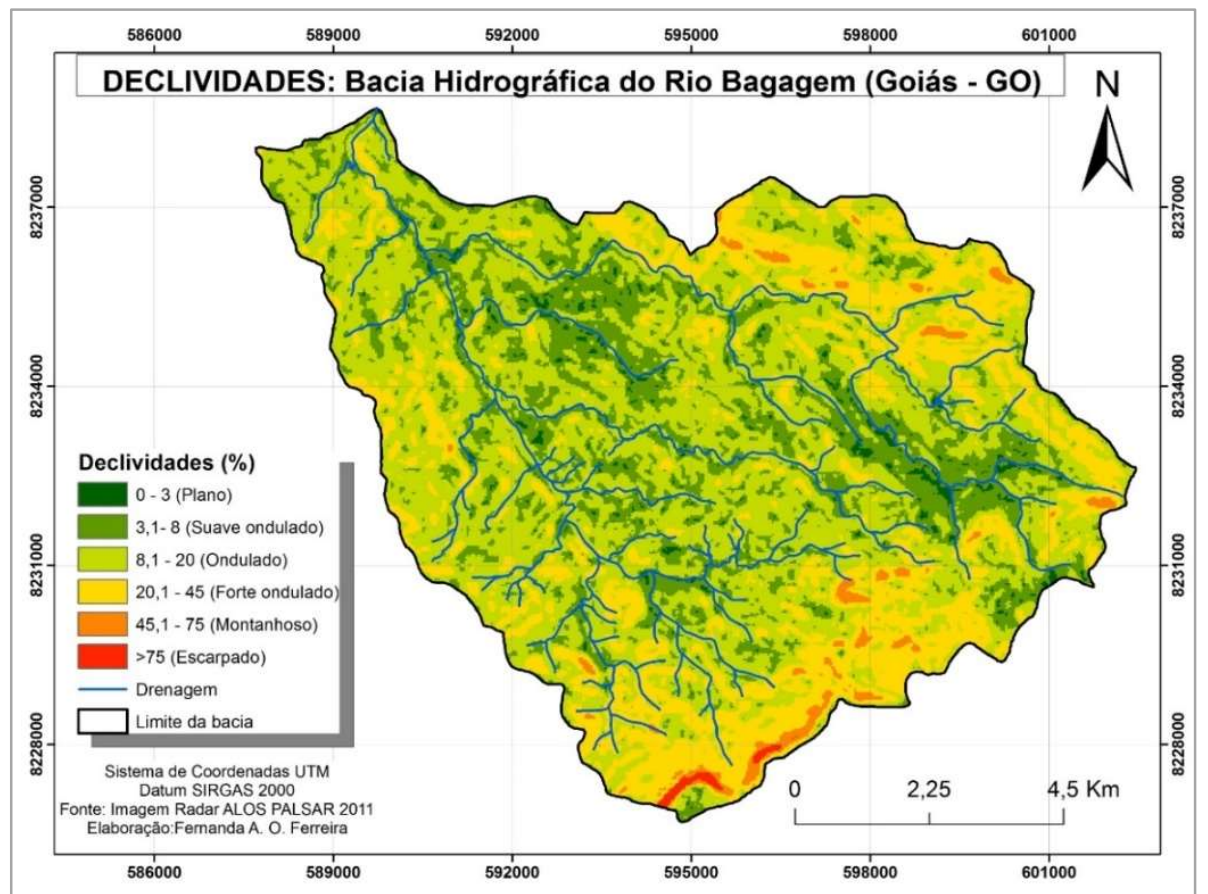

Fonte: Modelo Digital de Elevação - Alos Palsar/2011.

Tabela 2: Classes de declividade

\begin{tabular}{c|l|l|l}
\hline Formas de relevo & Classes (\%) & Área (\%) & Área $\left(\mathbf{K m}^{\mathbf{2}}\right)$ \\
\hline Plano & $0-3$ & 3,48 & 3,43 \\
\hline Suave ondulado & $3,1-8$ & 23,44 & 23,13 \\
\hline Ondulado & $8,1-20$ & 46,74 & 46,13 \\
\hline Forte ondulado & $20,1-45$ & 24,16 & 23,84 \\
\hline Montanhoso & $45,1-75$ & 1,97 & 1,94 \\
\hline Escarpado & $>75$ & 0,21 & 0,20 \\
\hline Total & - & 100 & 98,7 \\
\hline
\end{tabular}

Fonte: EMBRAPA (2009).

A bacia apresenta uma borda de declividades superiores a $20 \%$ nas porções NorteNordeste e Sul-Sudeste, que coincidem com os divisores de água, que apresentam relevos 
dobrados. As áreas planas, com declividades entre $0 \%$ a 3\%, ocorrem, predominantemente, próximas a calha das drenagens e próximas ao exutório da bacia.

Segundo Calil et al. (2012), topografias com declives acentuadas dificultam a infiltração, produzindo uma rede de drenagem mais densa e estas características podem ser percebidas no alto curso da BHRB, onde ocorrem as maiores declividades e, consequentemente, maior densidade das drenagens.

O conhecimento da declividade da bacia hidrográfica auxilia no cumprimento da legislação ambiental, por ser um indicador de áreas de risco e de preservação permanente; contribui no manejo e gestão dos recursos hídricos; na definição de áreas suscetíveis a enchentes e alagamentos; no planejamento adequado do uso do solo e na prevenção à perda de solo por processos erosivos e movimentos de massa (BRASIL, 2012; MAGESH et al., 2013).

Na BHRB foram identificados, a partir da base cartografia elaborada pela EMATERGO os tipos de solos: Argilossos, Cambissolos e Neossolos Litólicos (GOIÁS, 2006b). A distribuição espacial das classes solos pode ser observada na Figura 5.

Figura 5 - Solos da BHRB (Goiás - GO).

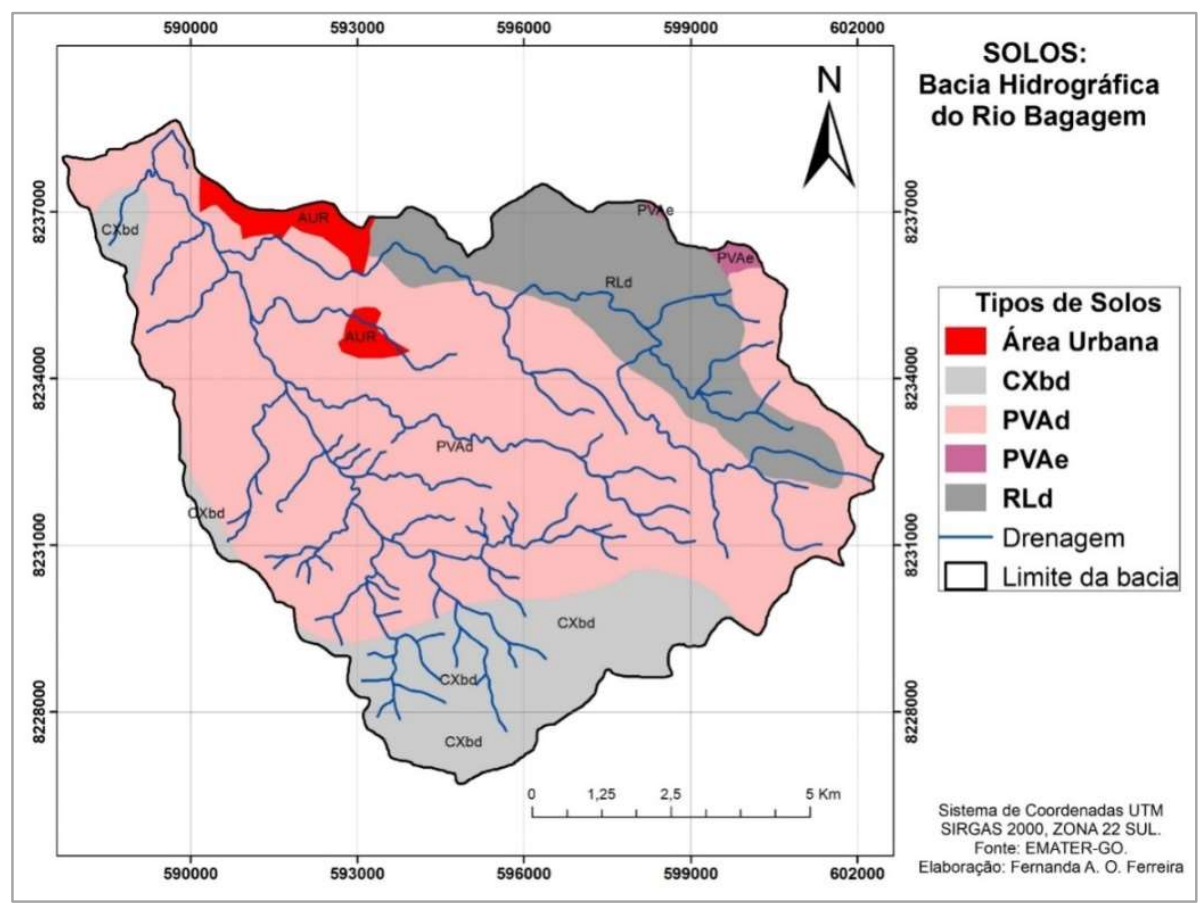

Fonte: Agência Goiana de Assistência Técnica, Extensão Rural e Pesquisa Agropecuária - EMATER.

O PVAd (Argissolo Vermelho-Amarelo distrófico) é o tipo de solo predominante na bacia, ocupando $65,34 \%$ da área. O PVAd ocorre em altitudes variadas, entre $422 \mathrm{~m}$ e $900 \mathrm{~m}$, se assentando sobre relevos planos, suave ondulados e ondulados, com declividades entre $0 \% \mathrm{e}$ 20\%. O PVAe (Argissolo Vermelho-Amarelo eutrófico - 0,40\%) compreende dois pequenos 
trechos $(0,405)$ a norte-nordeste da bacia, em declividades que variam de $8,1 \%$ a $20 \%$ (relevos ondulados) e elevações superiores a 800 metros.

Os Argissolos são constituídos por material mineral, apresentam um evidente aumento no teor de argila do horizonte A para o B. São de profundidade variável, desde bem a mal drenados, de cores avermelhadas ou amareladas (SANTOS et al., 2017). Segundo Goiás (2006b) os Argissolos da BHRB apresentam textura média a argilosa.

O CXbd (Cambissolo Háplico distrófico) compreende 16,44\% da área e ocorre predominantemente, na porção da Sul da bacia. Esse tipo de solo localiza-se em diferentes altitudes, que variam de $480 \mathrm{~m}$ a $1.054 \mathrm{~m}$ de altitude e em relevos forte ondulado, montanhoso e escarpado, em declividades acima de $20 \%$.

Os Cambissolos possuem horizonte B incipiente e geralmente pouco profundos por se desenvolverem em relevos mais inclinados. Na BHRB estes solos apresentam textura média com presença de cascalhos (GOIAS, 2006b; SANTOS et al., 2017).

O RLd (Neossolo Litólico distrófico) está disposto em uma única faixa contínua Leste/Sudeste e ocupa 15,39\% da área da bacia. Localiza-se em altitudes que variam de 540m a 900m, apresentando a menor diferença altimétrica, em relação aos demais tipos de solos, mas, com acentuada amplitude clinográfica, com declividades variando entre $8,1 \%$ a $75 \%$. Os Neossolos Litólicos ocorrem na bacia em relevos ondulados, forte-ondulados e montanhosos.

Os Neossolos Litólicos apresentam material intemperizado pouco espesso em função da baixa intensidade de atuação dos processos pedogenéticos. São solos que ocorrem geralmente em relevos movimentados, com ocorrência de afloramento rochoso (SANTOS et al., 2017). Na BHRB estes solos apresentam textura arenosa (GOIAS, 2006b).

$\mathrm{Na}$ Figura 6A temos a ocorrência de Argilosso, em relevo suave ondulado com cobertura de pastagem. Na Figura 6B, em primeiro plano, Cambissolo em relevo ondulado e, em segundo Plano, o front da Serra Dourada. Nestas áreas coexistem pastagens plantadas e cobertura de Cerrado. Na Figura 6C temos a ocorrência do Neossolo Litólico. Este tipo de solo ocorre em relevos de ondulado a fortemente ondulado e geralmente possuem coberturas campestres de Cerrado. 
Figura 6 - Paisagens com diferentes tipos de solos da BHRB.

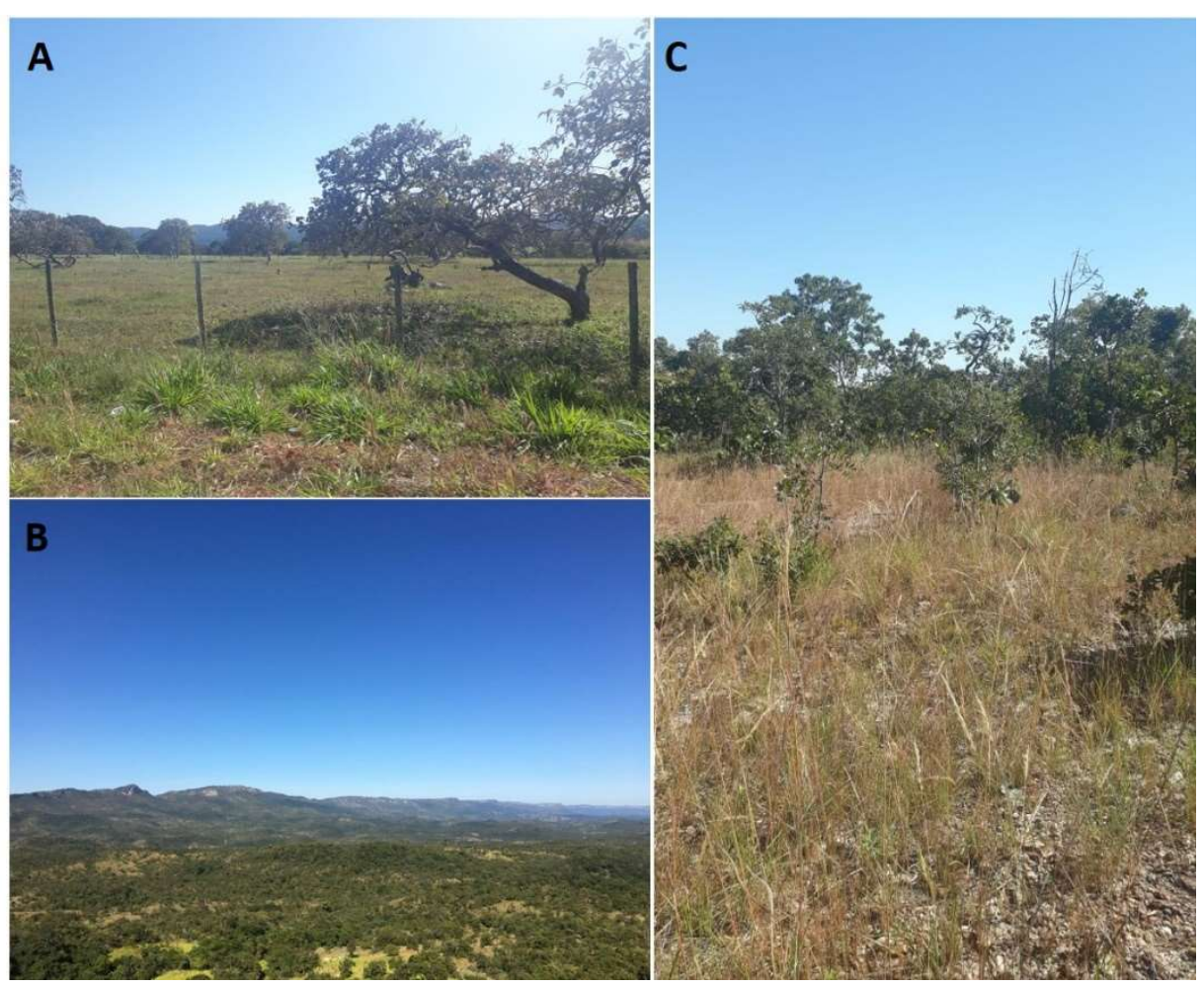

Fonte: Autores (2020).

Os resultados da caracterização geométrica e da rede de drenagem da BHRB são apresentados na Tabela 3 .

Tabela 3: Resultados da caracterização geométrica e da drenagem da BHRB (Goiás - GO).

\begin{tabular}{c|c}
\hline Variáveis & Resultado \\
\hline Densidade da drenagem & $1,63 \mathrm{Km} / \mathrm{Km}^{2}$ \\
\hline Perímetro & $48,36 \mathrm{Km}$ \\
\hline Ordem da bacia & $5^{\text {a } \text { ordem }}$ \\
\hline Índice de circularidade & 0,53 \\
\hline Coeficiente de sinuosidade & 0,89 \\
hidráulico & 0,5 \\
\hline Fator de forma & $613,5 \mathrm{~m} / \mathrm{Km}$ \\
\hline Coeficiente de manutenção & 1030,16 \\
\hline Índice de rugosidade & $3,02 \mathrm{~h}$ \\
\hline Tempo de concentração &
\end{tabular}

Fonte: Org. pelos autores (2020) 
A BHRB possui uma densidade de drenagem de 1,63 Km de canais por $\mathrm{Km}^{2}$, este valor indica uma densidade média, com tendência mediana de escoamento superficial. Densidades menores que 1,5 são consideradas baixas e maiores que 2,5, alta. Quanto maior a densidade, maior tendência ao escoamento superficial, menor infiltração e maior potencial a processos erosivos (STRAHLER, 1957; VILLELA; MATTOS, 1975).

A distância linear da área da BHRB (perímetro) é de 48,36 quilômetros. Possui um padrão de drenagem dendrítica e de quinta ordem. A extensão das drenagens é de $161,8 \mathrm{~km}$. A Figura 7 e a Tabela 4 apresentam as características de comprimento total e o percentual as ordens dos cursos d'água. Os cursos de primeira ordem representam 47,35\% do total da drenagem da bacia, totalizando $76,6 \mathrm{~km}$ de extensão. Estas características indicam que a bacia apresenta uma área bem drenada, considerando o perímetro, a quantidade e extensão dos canais (MAGESH et al., 2013).

Figura 7 - Mapa da ordem dos cursos d'água da BHRB (Goiás - GO)

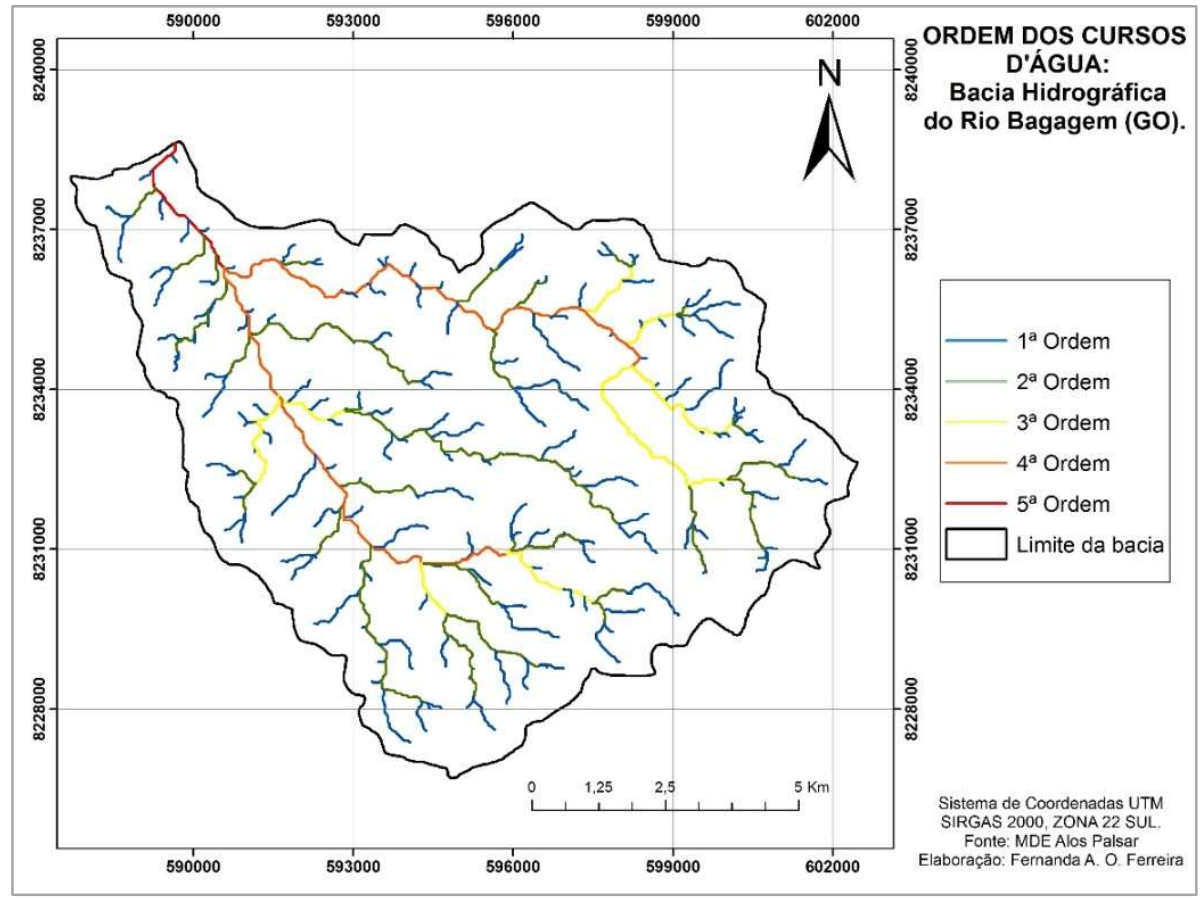

Fonte: Modelo Digital de Elevação - Alos Palsar/2011. 
Tabela 4 - Comprimento das ordens de cursos d'água da BHRB (Goiás - GO)

\begin{tabular}{c|c|c}
\hline Ordem & $\begin{array}{c}\text { Comprimento dos } \\
\text { Canais (Km) }\end{array}$ & $\%$ \\
\hline $1^{\mathrm{a}}$ & 76,6 & 47,35 \\
\hline $2^{\mathrm{a}}$ & 45,5 & 28,12 \\
\hline $3^{\mathrm{a}}$ & 16,7 & 10,32 \\
\hline $4^{\mathrm{a}}$ & 19,8 & 12,23 \\
\hline $5^{\mathrm{a}}$ & 3,2 & 1,97 \\
\hline & & 100 \\
\hline
\end{tabular}

Fonte: Org. pelos autores (2020)

O comprimento da bacia equivale a $15,7 \mathrm{~km}$ e largura máxima aproximada de $10 \mathrm{~km}$, revelando o seu alongamento como uma característica peculiar do tempo de percurso da água e a boa capacidade para recarga de águas subterrâneas, o que não ocorre em bacias mais curtas (BAJABAA; MASOUD; AMRI, 2013). A drenagem possui ramificação do tipo dendrítica e padrão retilíneo, já que o coeficiente de sinuosidade foi menor que $1,05(0,89)$. O padrão retilíneo é típico de bacias em as drenagens tem alto poder de dissecação e transporte de sedimentos. Valores de sinuosidade superiores a 1,05 indicam padrão sinuoso a meandrante (MORISAWA, 1975).

Quanto maior a ramificação da drenagem da bacia, mais eficiente pode ser considerado o seu sistema de drenagem e escoamento máximo, principalmente em áreas de altitudes elevadas e declividades acentuadas (STRAHLER, 1957). O curso principal da bacia possui $13,93 \mathrm{~km}$ de extensão e a drenagem total corresponde a $161,8 \mathrm{~km}$. 
Quanto ao índice de rugosidade relaciona a disponibilidade do escoamento hídrico superficial com seu potencial erosivo, expresso pela média das declividades. Quanto maior for esse índice (BHRB, igual a 1.030,16) maior será o risco de degradação da bacia quando as vertentes são íngremes e longas. Trata-se de um índice adimensional que corresponde à diferença altimétrica entre a foz e a maior altitude situada num determinado ponto da área da bacia, o que indica o desnível médio da bacia hidrográfica.

O coeficiente de manutenção da bacia hidrográfica é de $613,5 \mathrm{~m}^{3} / \mathrm{Km}$, que é um valor classificado como relativamente alto. Ou seja, nessa bacia é necessária uma área de $613,5 \mathrm{~m}^{3}$ para manter ativo um quilômetro de canal fluvial. Schumm (1956) afirma que o coeficiente de manutenção tem a finalidade de fornecer a área mínima necessária para a manutenção de $1 \mathrm{Km}$ de canal de escoamento, em condição perene.

O fator forma da $\operatorname{BHRB}(0,5)$ e o índice de circularidade $(0,53)$, indicam que a bacia tem formato oblongo, ou seja, sua largura é menor que o comprimento e estas características atribuem a bacia uma tendência de baixa a média possibilidade de ocorrência de enchentes. Esta condição é reforçada pelo de tempo de concentração (3,02 horas), ou seja, após um evento chuvoso, a concentração máxima do escoamento no exutório, pode ocorrer em aproximadamente 3 horas (VILLELA; MATTOS, 1975; PRUSKI et al., 2004).

As curvaturas em perfil e plana são indicadores de como ocorrem os fluxos nas vertentes, os quais associam-se as propriedades hidrológicas e de transporte de materiais. Enquanto o primeiro refere-se ao caráter convexo/côncavo do terreno, quando analisado em perfil, o segundo confere o caráter divergente/convergente dos fluxos superficiais sobre o terreno, analisado em uma projeção horizontal (VALERIANO, 2008). Com essas variações é possível descrever as características físicas de uma bacia de drenagem, em um esforço para entender os processos de escoamento superficial e de potencial a erosão.

O valor da curvatura pode ser usado para encontrar padrões de erosão do solo, bem como a distribuição de água na superficie. A curvatura em perfil afeta a aceleração e desaceleração do fluxo e, portanto, influencia a erosão e a deposição. A curvatura plana influencia a convergência e a divergência do fluxo como podemos observar na Figura 8. As formas de curvatura apresentadas na condição B da Figura 8 indicam a condição mais critica para concentração de fluxo e potencial para erosão do solo. 
Figura 8 - Esquema explicativo de Curvaturas de Relevo

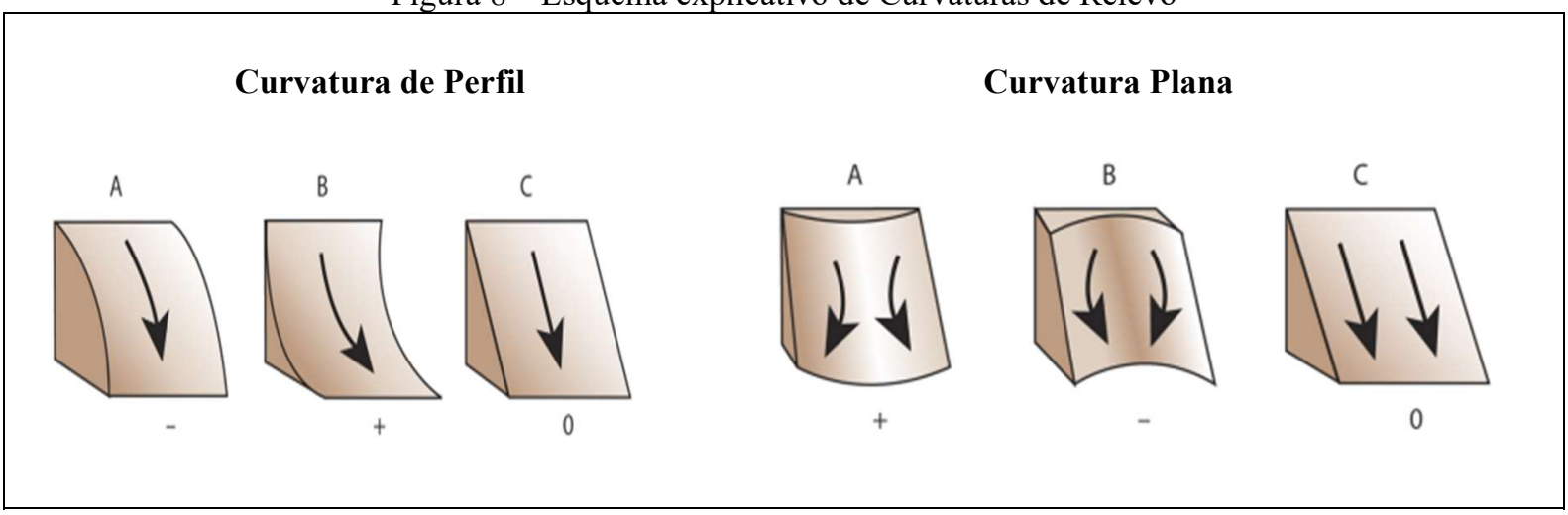

Fonte: Adaptação do texto, no arquivo: https://desktop.arcgis.com/en/arcmap/10.3/manage-data/raster-andimages/curvature-function.htm

O cálculo da curvatura se dá por procedimentos desenvolvidos em softwares de geoprocessamento e, segundo Christofoletti (1980), quando o resultado obtido é superior a 1,0, a vertente será predominantemente convexa e quando menos que 1,0 prevalece a concavidade. Dessa forma, na classificação dos resultados encontrados na BHRB (Figuras 8 e 9), concluiuse que os valores numéricos negativos indicam às vertentes convexas, portanto apresenta fluxo desacelerado em $36,20 \%$ da área da bacia. Nos valores positivos, em vertentes côncavas o fluxo é em 38,21\%, onde há aceleração do fluxo (condição B da curvatura em perfil na Figura 9) e os valores próximos de zero, obtidos em $25,59 \%$ da área, indica uma superfície linear ou retilíneas (Figura 9).

Figura 9 - Mapa de curvatura em perfil da BHRB (Goiás - GO)

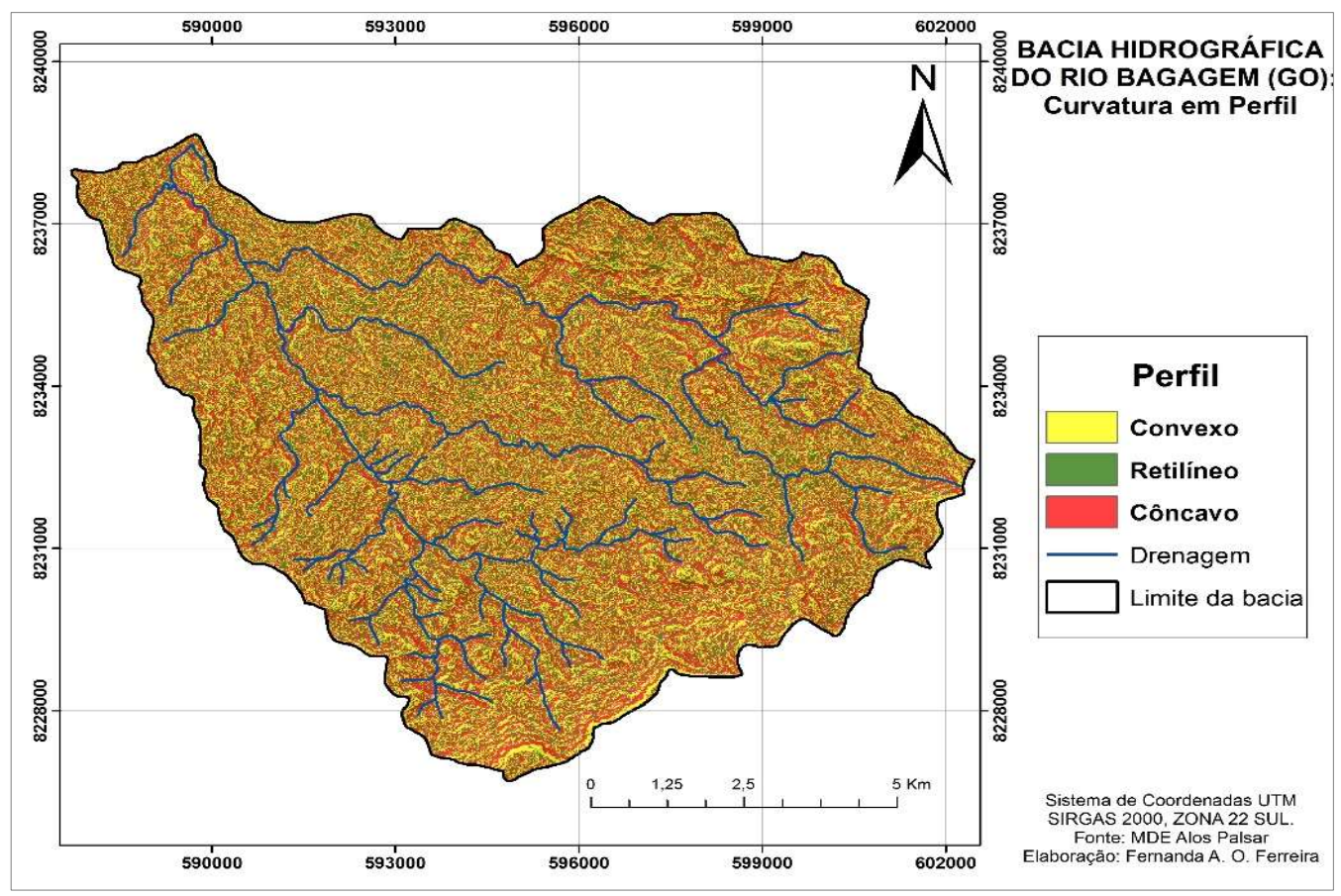

Fonte: Modelo Digital de Elevação - Alos Palsar/2011. 
A representação do relevo em curvatura plana (Figura 10) refere-se à convergência e divergência do fluxo da água em uma vertente. De acordo com Guerra (2003) e Valeriano (2008) as vertentes côncavas concentram o fluxo do escoamento superficial, tornando estas vulneráveis a erosão e inundação e, as vertentes convexas, provocam dispersão no escoamento.

Figura 10 - Mapa de curvatura plana da BHRB (Goiás - GO)

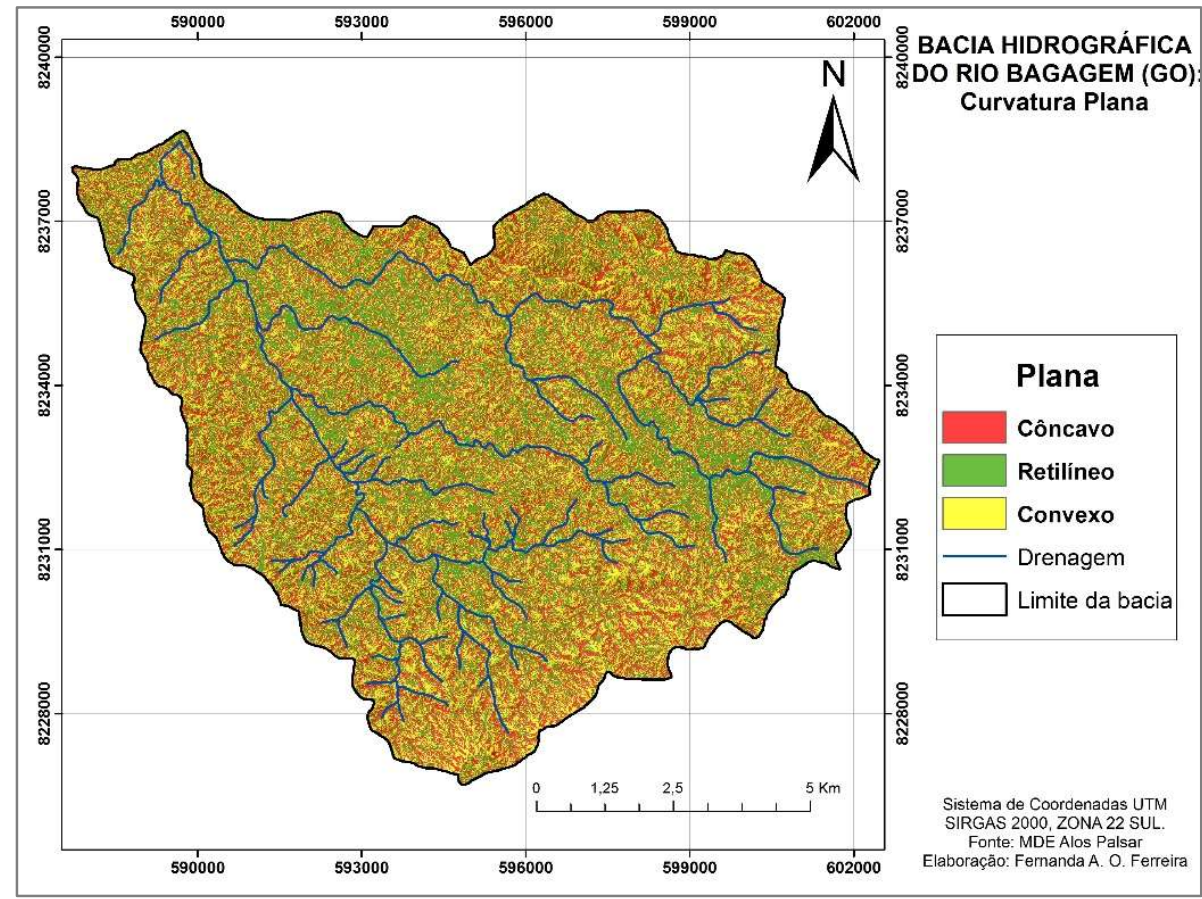

Fonte: Modelo Digital de Elevação - Alos Palsar/2011.

$\mathrm{Na} \mathrm{BHRB}$ foram encontrados valores numéricos positivos que indicam que a superfície é lateralmente convexa, em $34,13 \%$ da área da bacia, condição esta que provoca a dispersão no escoamento. Já em $32,43 \%$ da área, foram encontrados valores numéricos negativos, que indicam vertentes côncavas, portanto, áreas com potencial de concentração no fluxo do escoamento superficial, tornando-as suscetíveis a erosão e a inundação (Condição B da curvatura plana na Figura 8). E o valor zero, representado por 33,44\% em áreas que indicam superfície linear ou retilínea (Figura 10). 


\section{CONSIDERAÇÕES FINAIS}

A BHRB possui uma dinâmica geomorfométrica e hidrológica com indicação de baixo a médio potencial para ocorrência de enchentes, devido a seu formato oblongo. A rede de drenagem apresenta cinco ordens e uma densidade (regular e dendrítica), indicando que a bacia possui boa ocorrência e distribuição das águas. No entanto, o coeficiente de manutenção, com valor relativamente alto, indica dificuldade na manutenção de drenagens perenes.

A alta amplitude altimétrica e de declividades, associada aos tipos de solos, sugerem uma preocupação acerca das formas de uso e manejo da bacia, no intuito de mitigar de processos erosivos e impactos nos corpos hídricos. Quanto a curvatura de perfil e plana das vertentes, os resultados indicaram que mais um 1/3 da área da bacia presenta fluxo acelerado e concentrado do escoamento superficial, tornando-as suscetíveis a erosão e a inundação.

A caracterização geomorfométrica se apresentam como metodologias eficazes no diagnóstico das condições físicas e hidrológicas de bacias hidrográficas, e seus resultados podem subsidiar ações de gestão e manejo das áreas, com vistas à mitigação de processos degradação dos solos e manutenção das drenagens em situações de escassez água.

\section{REFERÊNCIAS}

AHER, P.D.; ADINARAYANA, J.; GORANTIWAR, S.D. Quantification of morphometric characterization and prioritization for management planning in semi-arid tropics of India: A remote sensing and GIS approach. Journal of Hydrology, v. 511, p. 850-860, 2014.

BAJABAA, S.; MASOUD, M.; Al-AMRI, N. Flash flood hazard mapping based on quantitative hydrology, geomorphology and GIS techniques (case study of Wadi Al Lith, Saudi Arabia). Arabian Journal of Geosciences, v. 7, p. 2469-2481, 2013.

BERTONI, J.; LOMBARDI NETO, F. Conservação do solo. 9. ed. São Paulo: Ícone, 2014. $355 \mathrm{p}$.

BERTRAND, G. Paisagem e geografia física global: Esboço metodológico. R. RA'E GA, Curitiba, n. 8, p. 141-152, 2004.

BOTELHO, R. G. M.; SILVA, A. S. Bacia hidrográfica e Qualidade Ambiental. In: VITTE, A. C.; GUERRA, A. J. T (Org.). Reflexões sobre a Geografia Física no Brasil. 6. ed. Rio de Janeiro: Bertrand Brasil, 2010. p. 153-192.).

BRASIL. Lei $\mathbf{n}^{\mathbf{0}} \mathbf{1 2 . 6 5 1 / 2 0 1 2}$, de 15 de 25 de maio de 2012 do Código Florestal Federal.

CAVALCANTI, M. A.; LOPES, L. M.; PONTES, M. N. C. Contribuição ao entendimento do fenômeno das enchentes do Rio Vermelho na cidade de Goiás, GO. Boletim Goiano de Geografia. Goiânia - Goiás - Brasil v. 28 n. 1 p. 167-186 jan. / jun. 2008.

CAlil, P. M.; OliveiRA, L. F. C. de; KLIEMANN, H. J.; OliVEIRA, V. A. de. Caracterização geomorfométrica e do uso do solo da bacia hidrográfica do Alto Meia Ponte, 
Goiás. Revista Brasileira de Engenharia Agrícola e Ambiental, Campina Grande, v. 16, n. 4, p. 433-442, 2012.

CHRISTOFOLETTI. A. Análise morfométrica de bacias hidrográficas. Notícias Geomorfológicas, Campinas, v. 18, n. 9, p. 35-64, 1969.

CAMPANHARO, W. A. Diagnostico físico da bacia do rio Santa Maria do Doce-ES. 2010. 66 f. Monografia (Graduação) - Departamento de Engenharia Florestal, Universidade Federal do Espírito Santo, Jerônimo Monteiro, ES.

CHRISTOFOLETTI, A. Geomorfologia. 2a ed. São Paulo: Ed. Edgard Blücher Ltda, 1980, $188 \mathrm{p}$.

EMBRAPA. Centro Nacional de Pesquisa de Solos (Rio de Janeiro, RJ). Sistema brasileiro de classificação de solos. Rio de Janeiro: EMBRAPA-SPI, 2009. xxvi, 412p. : il.

FARIA, M. M.; ZACCHI, R. C.; FERREIRA, E. S. Caracterização morfométrica e biológica da Bacia Hidrográfica do Córrego Serafim, Sub-Bacia do Rio Paraibuna, Juiz de Fora MG. In: SIMPÓSIO BRASILEIRO DE GEOGRAFIA FÍSICA APLICADA, 13, 2009, Viçosa, MG. [Anais...] Viçosa, MG: Editora da Universidade Federal de Viçosa, 13. 2009.

GOIÁS (Estado). Secretária de Indústria de Comércio. Superintendência de Geologia e Mineração. Geomorfologia do Estado de Goiás e Distrito Federal. Por Edgardo M. Latrubesse, Thiago Morato de Carvalho. Goiânia, 2006a.

GOIÁS (Estado). Agencia Ambiental de Goiás. Base de dados: Determinação de áreas prioritárias para unidades de conservação. WWF-Embrapa-IBGE $2006 \mathrm{~b}$.

GUERRA, A. J. T. Encostas e a questão ambiental. In: CUNHA, S. B; GUERRA, A. J. T. A. (Org.). Questão Ambiental: Diferentes abordagens. Rio de Janeiro: Bertrand Brasil, 2003, p. 191-218.

LEAL, I. R.; TABARELLI, M.; SILVA, J.M.C. (orgs.). Ecologia e conservação da caatinga. Editora Universitária, Universidade Federal de Pernambuco, Recife. 2003.

LOPES, E. R. N. et al. Modelagem ambiental de bacias hidrográficas: caracterização morfométrica e pedológica da bacia do Rio Una - Ibiúna, Brasil. Geosul, Florianópolis, v. 33, n. 66, p.105-127, jan./abr. 2018.

MAGESH, N. S. et al. Geographical information system-based morphometric analysis of Bharathapuzha river basin, Kerala, India. Applied Water Science, v. 3, p. 467-477, 2013.

MORISAWA, M. Tectonics and geomorphic models. In: MELHORN, W. N.; FLEMAL, R. C.(edits.). Theories of Landform Development. London: G. Allen \& Unwin, 1975. p.199216.

PORTO, M. F. A.; PORTO, R. L. L. Gestão de Bacias Hidrográficas. Estudos Avançados, 22 (63), 2008.

PRUSKI, F. F.; BRANDÃO, V. D. S.; SILVA, D. D. D. Escoamento superficial. 2. ed. Viçosa: Editora UFV, 2004. 87 p.

SANTOS, H. G. dos. et al. Proposta de atualização da terceira edição do Sistema Brasileiro de Classificação de Solos: ano 2017. Rio de Janeiro: Embrapa Solos, 2017. 159 p.

SCHUMM, S. A. Evolution of drainage systems and slopes in badlands of Perth Amboy. GeologicalSociety of AmericaBulletin, New York, v. 67, n. 5, p. 597-646, May 1956. 
SHELEME, B. Characterization of soils along a toposequence in Gununo area, southern Ethiopia. Journal of Science and Development, v. 1, n. 1, p. 31-41, 2011.

SOUZA, S. O.; OLIVEIRA, R. C. de. Considerações sobre a geografia física: conceitos, métodos e aplicações. Os Desafios da Geografia Física na Fronteira do Conhecimento, p.3483-3494, 2017.

SOTCHAVA, Viktor B. O estudo de Geossistemas. Métodos em Questão. N. 16. São Paulo: USP/IG, 1977.

STRAHLER, A. N. Quantitative analysis of watershed geomorphology. Transactions of the American Geophysical Union, v. 38, n. 6, p.913-920, 1957.

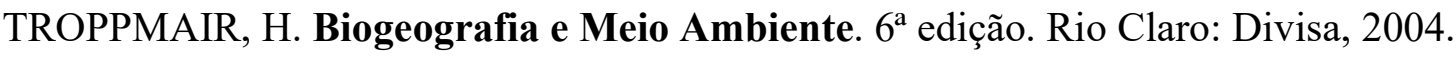

VALERIANO, M. M. Dados Topográficos. In: FLORENZANO, T. G. (Org.), Geomorfologia: conceitos e tecnologias atuais. Oficina de Textos, São Paulo, pp. 72-104, 2008.

VILlELA, S. M.; MATTOS, A. Hidrologia aplicada. São Paulo: McGraw-Hill do Brasil, 1975. $245 \mathrm{p}$

VIEIRA, Pedro Alves; FERREIRA, Nilson Clementino; FERREIRA, Laerte Guimarães. Análise da vulnerabilidade natural da paisagem em relação aos diferentes níveis de ocupação da bacia hidrográfica do Rio Vermelho, Estado de Goiás. Sociedade \& Natureza, v. 26, n. 2, p. 385-400, maio 2014. 